$1 N-35649$

NASA Contractor Report 179529

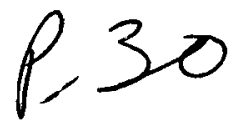

\title{
Grain Boundary Oxidation and Fatigue Crack Growth at Elevated Temperatures
}

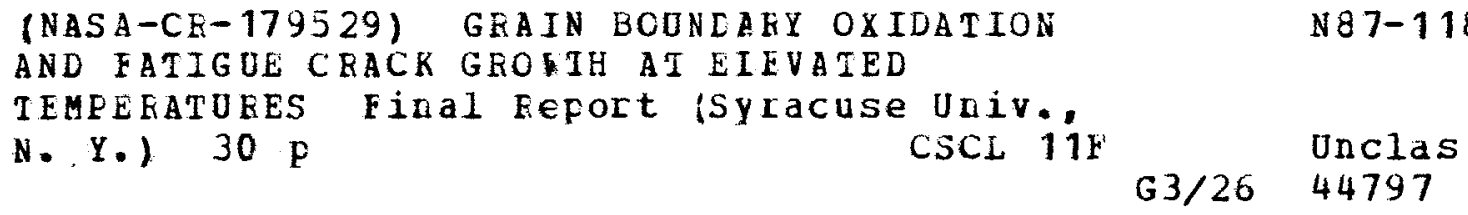

H.W. Liu and Yoshiki Oshida

Syracuse University

Syracuse, New York

October 1986

Prepared for

Lewis Research Center

Under Grant NAG3-348

\section{nensn}




\section{INTRODUCTION}

Fatigue crack growth in the air at elevated temperatures is of ten faster than the rate at room temperature. The accelerated fatigue crack growth has been attributed to creep and/or oxidation $[1,2,3]$. Creep induces grain boundary void formation and grain boundary cavitation, and the formation and the growth of grain boundary voids and cavities will accelerate fatigue crack growth.

Hull and Rimmer [4] studied the growth of grain boundary voids under stress in polycrystal copper wire. The nucleation of creep cavities in a copper base alloy was observed by Fleck, Taplin, and Beevers [5]. The nucleation and growth of cavities in iron during creep deformation at elevated temperatures was studied by Cane and Greenwood [6]. Grain boundary cavity and void nucleations during creep under a sustained stress have been analyzed by a number of investigators $[7$ to 16$]$.

The cavity growth rate is related to either grain boundary vacancy diffusion or surface diffusion. The cavity growth rate has the form of the Arrhenius relation. However, grain boundary cavity nucleation and growth under a cyclic load and the relation between the growth rates of grain boundary cavities and fatigue crack have yet to be studied.

Gibb's free energies of metal oxide formation are negative. When in direct contact with oxygen, metals oxidize easily, and the rate of oxidation depends on the rate of diffusion of oxygen or metal through the oxide layer. Grain boundary is a site of high energy and a path of rapid diffusion. Therefore, the oxidation 


\section{GRAIN BOUNDARY OXIDATION PENETRATION}

Oshida and Liu [31] have studied grain boundary oxidation penetration in a nickel base superalloy, TAZ-8A, under a stress-free condition. Each disk coupon, $15 \mathrm{~mm}$ in diameter and $5 \mathrm{~mm}$ in thickness, was oxidized in air. The oxidation temperatures were 600,800 , and $1000^{\circ} \mathrm{C}$, and the exposure times varied from 100 to 1000 hours. After oxidation, each coupon was sectioned, and the sectioned surface was examined under an optical microscope. Figure 1 shows the picture of a cross section of a test coupon. The grain boundary oxide penetrates deeper than the surface oxide.

On each sectioned surface, the grain boundary oxidation penetration varied widely from one grain boundary to another. The maximum grain boundary oxidation penetration depth, $a_{m}$, of a sectioned surface was measured. After the measurement, a thin layer of the coupon, approximately $80 \mu \mathrm{m}$ thick, was ground off, the new surface was polished, and another maximum grain boundary oxidation penetration depth was measured. This process was repeated twelve times for each test coupon. Altogether, 144 data points were collected at the three oxidation temperatures, $T$, and at various exposure times, $t$. The regression analysis of the data gives the following empirical relation.

$$
a_{m}=\alpha t^{n} \exp (-Q / R T)
$$

where $a_{m}$ is in cm; $t$, in seconds; the activation energy, $Q$ is $4.25 \mathrm{Kcal} / \mathrm{mol}$; $\mathrm{T}$ in ${ }^{\circ} \mathrm{K}$; and $\mathrm{R}=1.987 \mathrm{cal} / \mathrm{mol} /{ }^{\circ} \mathrm{K} . \alpha=1.34 \times 10^{-3} \cdot \mathrm{n}=0.25$. The coefficient of auto-correlation is 0.96 . 
Reuchet et al. $[32,33]$ studied oxidized depth of MC carbides in a cobalt-base superalloy (Mar M509). They found a time exponent $\mathrm{n}=0.25$. Stott et al. [34,35] studied intergranular oxidation in Ni-Cr alloys, and they found $n=0.48$ for $60 \mathrm{~N} i-40 \mathrm{Cr}$ alloy, 0.51 for $\mathrm{Ni}-15.1 \mathrm{Cr}-1.1 \mathrm{Al}$ alloy, and 0.66 for $\mathrm{Ni}-28.8 \mathrm{Cr}-1.0 \mathrm{Al}$ alloy. They concluded that the intergranular oxide penetration depth in $\mathrm{NI}-\mathrm{Cr}$ alloys followed a parabolic rate relation.

Grain boundary oxide penetration is controlled by grain boundary diffusion of axygen, and grain boundary diffusion is a function of the relative orientations of the two nefghboring grains $[36,37,38\}$ as shown in Figure 2. The variation of grain boundary diffusion rate could be one of the causes for the statistical scatter of the measured oxide penetration depths.

At any given combination of temperature, $T$, and exposure time, $t$, the value of $\alpha_{i}$ can be calculated from the measured $a_{m i}$-value by using Equation (1). The variation of the calculated $\alpha$-values reflects the statistical scatter of the measured $a_{m}$-values. The Weibull plnt of all of the 144 values of $\alpha_{i}$ is shown in Figure 3 . The Weibull distibution function is

$$
\left[1-P\left(\alpha_{i}\right)\right]=\exp \left[-\left(\frac{\alpha_{i}-\alpha_{u} b}{\alpha_{0}}\right)\right]=\exp \left[-\frac{\left(\alpha_{i}-\alpha_{u}\right)^{b}}{\eta_{\alpha}}\right]
$$

where $P\left(\alpha_{i}\right)$ is the probability of finding an $\alpha$-value less than $\alpha_{i}$ on a sectioned surface. $\alpha_{u}$ is the location parameter. It is the horizontal shift for each of the data points so that all of the points will be on a straight line in the plot. $b$ is the slope of the line, and it is called shape parameter or Weibull modulus. $\alpha_{0}$ and $\eta_{0}=\alpha_{0}^{b}$ set the scale for the Weibull distribution. $\alpha_{0}$ is the value of $\left(\alpha_{i}-\alpha_{u}\right)$ at $\ln \ln \left\{1 /\left[1-P\left(\alpha_{i}\right)\right]\right\}=0$. For the data in Figure 3, $\alpha_{u}=0.53 \times 10^{-3}, b=1.85$, and $\alpha_{0}=0.51 \times 10^{-3}$. The experimental details and a more 
detailed discussion on the oxide formation and the statistical scatter are given in Reference [31].

If the grain boundary oxidation penetration rate is controlled by the grain boundary diffusion rate, and if grain boundary diffusion can be considered as a one-dimensional flow, the oxidation penetration depth can be written as

$$
a_{m}=\alpha t^{0.5} \exp \left(-Q_{g b} / 2 R T\right)
$$

$Q_{g b}$ is the activation energy of grain boundary diffusion. This result is certainly different from the empirical relation, Equation (1).

The coefficient of grain boundary diffusion is several orders of magnitude higher than that of lattice diffusion. Nevertheless, the grain boundary diffusion kinetics are affected by lattice diffusion. Whipple [39] has analyzed the effects of lattice diffusion on grain boundary diffusion. These effects for TAZ-8A have yet to be assessed quantitatively.

The kinetics of grain boundary oxide penetration will certainly be related to the morphology of the oxide. Grain boundary oxides have two different shapes: pancake type and cone type. Furthermore, the detailed chemical processes of oxidation have also to be taken into consideration in a theoretical analysis. Grain boundary oxide penetration is further complicated by the internal stresses caused by the oxide formation.

For the moment, Equation (1) can be treated as an empirical relation. Perhaps, the oxide penetration depth at a crack tip can be written in the form

$$
\frac{a}{C}=F\left(\frac{D t}{C}\right)
$$


where $D$ is diffusion coefficient, and $C$ is the magnitude of the diffusion jumping vector or interatomic spacing. The details of the function, F, are unknown. Assuming a simple power relation, we have

$$
\begin{aligned}
& a_{m}=\beta C\left(D_{0} t / C\right)^{n} \exp (-n \Delta H / R T)=\alpha t^{n} \exp (-Q / R T) \\
& \text { the diffusion coefficient at } T=0, \alpha, \beta \text {, and } n \text { are }
\end{aligned}
$$

constants. The apparent activation energy, Q, for grain boundary

oxide penetration is not necessarily equal to the activation energy

of diffusion, $\Delta \mathrm{H}$. If the penetration depth is dependent on both

grain boundary and bulk diffusions, $a_{m}$ is related to both $\left(D_{g b} t / C\right)$

and $\left(D_{b} t / C\right) . \quad D_{g b}$ and $D_{b}$ are grain boundary and bulk diffusion

coefficients. 
III. THE INTERMITTENT MICRO-RUPTURE MODEL FOR HIGH TEMPERATURE FATIGUE CRACK GROWTH

Fatigue crack growth at elevated temperatures is sensitive to both frequency and temperature. Figures $4 \mathrm{a}[40,41]$ and $4 \mathrm{~b}[42]$ show the frequency and temperature effects on the fatigue crack growth in IN-100. The data merge onto two limiting lines, one on the right and one on the left of the data band. Along these two limiting lines, the fatigue crack growth rate is independent of frequency and temperature. The right hand side limiting line is for high frequency and low temperature. The left hand side limiting line is for high temperature and low frequency. However, it is not certain that the left limiting line always exits. Between these two limiting lines, da/dN is sensitive to both frequency and temperature. "da/dN" increases with temperature and decreases with an increase in frequency.

At a constant $\Delta \mathrm{K}$ level and at a given test temperature, the more detailed frequency effects on the facigue crack growth rate are shown in Figure $5[41,43-48]$. The cyclic crack growth rates, $\mathrm{da} / \mathrm{dN}$, of a number of materials in the low frequency region are inversely proportional to cyclic frequency, $v$, and are linearly proportional to the length of the time period per cycle. The time rate of the fatigue crack growth, da/dt $=(\mathrm{da} / \mathrm{dN})(1 / \mathrm{v})$, is constant. In this region, the fatigue crack growth is intergranular. The fatigue crack growth rate decreases as cyclic frequency increases. At a very high frequency, the fatigue crack growth rate is independent of frequency and temperature. It corresponds to the right 
hand side limiting line. At such a high frequency, the fatigue crack growth is transgranular, and the abserved fatigue striations on a crack surface indicate that fatigue crack growth is caused primarily by crack tip cyclic plastic deformation.

In the intermediate frequency region, a fatigue crack grows in a mixed mode both intergranularly and transgranularly, and the growth rate is sensitive to both frequency and temperature.

For constant-K tests at elevated temperatures, two crack growth features are common: (i) the time rate of crack growth is constant, (i.e. $d a / d t=$ constant $)$ and $(i i)$ crack growth is intergranular. Crack growth at constant- $\mathrm{K}$ is often referred to as creep crack growth.

In the low frequency region, $\mathrm{da} / \mathrm{dN}$ is inversely proportional to frequency, $v$, and frequency is the inverse of the time period per cycle. Therefore, in the low frequency region, the time rate of fatigue crack growth is also constant as the creep crack growth rate. Furthermore, fatigue crack growth in this region is also intergranular. Therefore, fatigue crack growth in the low frequency region, where the intergranular crack growth rate $\mathrm{da} / \mathrm{dN}$ is inversely proportional to $v$, is often referred to as creep crack growth.

However, a few questions remain unclear. Does creep crack growth imply that the fatigue accelerated crack growth is caused by grain boundary void nucleation and growth and/or by crack tip creep deformation? Does the inverse relation between $\mathrm{da} / \mathrm{dN}$ and $v$ preclude the possibilty that grain boundary oxidation is the underlying cause for the accelerated fatigue crack growth at elevated temperatures? In this section, oxidation will be analyzed as a possible cause of the accelerated fatigue crack growth at elevated temperatures. 
In the low frequency region of Figure 5, the fatigue crack growth rates of Inconel 718 , Inconel $\mathrm{X}-750$, Astroloy at $700^{\circ} \mathrm{C}$ and $760^{\circ} \mathrm{C}$, and Cr-Mo steels, are inversely proportional to frequency. The cyclic loading patterns are also shown in the figure. For Inconel 718 and Astroloy, a hold time, $\Delta t_{H}$ at $\mathrm{K}_{\max }$ was applied. For Inconel $\mathrm{X}-750$, Cr-Mo steels, and Astroloy at $700^{\circ} \mathrm{C}$, a triangular loading pattern was used.

Antolovich et al. [49] found that oxide in a smooth specimen ruptured when the applied stress reached a critical value. The applied stress at rupture is inversely related to the oxide size. The critical crack tip oxide size at rupture must be related to the stress intensity factor, K. The oxygen arriving at a crack tip will have to diffuse along the grain boundary into the region ahead of the crack tip forming oxide. When the crack tip grain boundary oxide reaches the critical size, $\delta a$, the oxide will rupture and the crack will grow by the amount of $\delta a$. Once the crack tip advances to its new position, this process of grain boundary diffusion, grain boundary oxidation, rupturing of the grain boundary oxide, and crack advancing will be repeated again. This process of micro-ruptures of crack tip grain boundary oxides can reoccur Intermittently many times during a fatigue cycle. Coffin (1) has suggested this process as a mechanism of the accelerated fatigue crack growth at elevated temperatures. In this paper, a quantitative model of intermittent micro-ruptures of grain boundary oxide will be constructed and it will be shown that the intermittent micro-ruptures of grain boundary oxide can lead to a fatigue crack growth rate inversely proportional to $v$. The tests with hold time will be analyzed first. During the 
hold time, $\Delta t_{H}$ at $K_{\text {max }}$, a number of intermittent micro-ruptures will take place. Assume that every micro-rupture will advance the crack to the "tip" of the oxide. Therefore, the time increment, $\delta t$, necessary for the oxide starting from the crack tip, to reach the critical rupture size, $\delta a$, is given by Equations (4) and (5). For a simple power relation, we have

$$
\delta t=\left(C / D_{g b}\right)(\delta a / \beta C)^{1 / n}
$$

The number of micro-ruptures during $\Delta t_{H}$ is

$$
\mathrm{m}=\Delta \mathrm{t}_{\mathrm{H}} / \delta \mathrm{t}=\left(\Delta \mathrm{t}_{\mathrm{H}} \mathrm{D}_{\mathrm{gb}} / \mathrm{C}\right)(B \mathrm{C} / \delta \mathrm{a})^{1 / \mathrm{n}}
$$

"m" is proportional to $\Delta t_{H^{*}}$ Both $m$ and $\Delta t_{H}$ are inversely proportional to frequency, $v$.

Fatigue crack growth per cycle is the sum of the rapid and intermittent micro-ruptures per cycle.

$$
\frac{\mathrm{da}}{\mathrm{dN}}=\mathrm{m \delta a}
$$

Substituting Equation (7) into Equation (8), we have

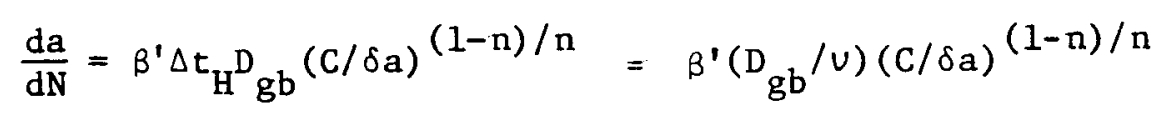

$\mathrm{da} / \mathrm{dN}$ are inversely proportional to $v$. 
For $n=0.25, \mathrm{da} / \mathrm{dN}$ is inversely proportional to $\mathrm{a}^{3}$. Fatigue crack growth rate increases rapidly as $\delta a$ becomes small. $\delta a$ is smaller if the oxide is more brittle.

For a given material, $\delta \mathrm{a}$ and $\mathrm{m}$ are functions of $\mathrm{K}_{\max }$ during the hold time. Therefore, we have

$$
\frac{\mathrm{da}}{\mathrm{dN}}=\frac{1}{v} \mathrm{f}\left(\mathrm{K}_{\max }, \mathrm{T}\right)
$$

as shown by the data in the low frequency region in Figure 5 .

For the triangular loading pattern, let us assume that the critical crack tip oxide size, $\delta a$, at rupture is a function of the crack tip fleld, the crack tip field can be characterized by the stress intensity factor, $K$, and the crack tip field is independent of the cyclic frequency, $v$.

Figure 6 shows the triangular loading at two different frequencies. (We use the triangular loading as an illustration, but the following analysis is applicable to any other wave shape). If the crack tip fields at $K_{i}$ are the same at both of these two frequenices, the critical oxide penetration depths, $\delta a_{i}$ at rupture must be the same. During the time interval $\Delta t_{i}$ at $k_{i}$, a number of intermittent micro-ruptures will take place. At the same $\mathrm{K}_{i}$ level, the time increment, $\delta t_{i}$, necessary for the oxide to reach the critical size, is directly related to $\delta a_{i}$, Equation (6). The number of micro-ruptures, $m_{i}$, during the time interval, $\Delta t_{i}$ at $k_{i}$ is simply $\Delta t_{i} / \delta t_{i}$. "m" is proportional to $\Delta t$ and inversely proportional to frequency, $v$. This inverse relation between $m_{i}, \Delta t_{i}$, and $v$ is true at any $k_{i}-1$ evel.

The fatigue crack growth rate is the sum of the rapid and intermittent micro-ruptures at all the $\mathrm{K}_{i}$-levels during one cycle. 


$$
\frac{\mathrm{da}}{\mathrm{dN}}=\sum_{i} \mathrm{~m}_{i} \delta a_{i}
$$

" $\mathrm{m}^{\mathrm{i} i}$ is inversely proportional to $v$ at any $\mathrm{K}$-level. Therefore, $\mathrm{da} / \mathrm{dN}$ is inversely proportional to $v$.

The crack growth rate at a frequency $v$ can also be written as

$$
\left.\left.\frac{d a}{d N}\right)_{v}=\frac{v_{0}}{v} \frac{d a}{d N}\right)_{0}=\frac{v_{0}}{v} f\left(K_{\max }, \Delta K, T\right)
$$

$\left.\frac{\mathrm{da}}{\mathrm{dN}}\right)_{v_{0}}$ is the crack growth rate at a reference frequency, $v_{0}$. Equations (11) and (12) for arbitrary wave shapes are derived with the assumption that $\mathrm{K}$ is capable of characterizing the crack tip field and the crack tip field is not affected by cyclic frequency. However, the creep stress relaxation at a crack tip and the internal stress caused by oxidation have not been taken into account. They could be the reasons why some of the data in the low frequency region in Figure 5 do not obey the inverse relation. No such assumption is necessary for the derivation of Equation (8) for the crack growth rate with a holdtime at $K_{\max } \cdot$

In the low frequency region, when there is enough time for repeated grain boundary oxidation penetrations and repeated micro-ruptures of the oxides to take place, the fatigue crack growth rate along an embrittled grain boundary is inversely proportional to the frequency, and crack growth is intergranular. Therefore, these two crack growth features of inverse relation of da/dN with frequency and intergranular crack growth can be caused by grain boundary oxidation, and they cannot be attributed to creep cracking without 
additional substantive experimental evidence. Such inverse relationship in the low frequency region is shown in Figure 5 for Inconel 718, Inconel X-750, Astroloy, and Cr-Mo steels.

In order to accelerate fatigue crack growth, the oxygen atoms must reach the crack tip during the process of crack growth rather than after. Therefore, the accelerated fatigue crack growth is closely related to the rate of the transport of oxygen.

For a given material at a given applied $\mathrm{K}$ level, there exists an intrinsic crack growth rate, $(\mathrm{da} / \mathrm{dN})_{\mathrm{f}}$, which is caused by the fatigue process of cyclic crack tip plastic deformation alone, without the effect of oxidation. At a very high frequency, the diffusing species does not have enough time to travel in order to follow the crack tip. Therefore, oxidation does not have much effect on the fatigue crack growth. The fatigue crack growth is caused by cyclic plastic deformation, and the growth is transgranular. The $\mathrm{da} / \mathrm{dN}$ is not limited by the transport process, and it is independent of frequency and temperature, so that the crack growth rate data in Figures $4 \mathrm{a}$ and $4 \mathrm{~b}$ will merge to the right hand side limiting line of high frequency and low temperature and the data in Figure 5 will level off in the high frequency region. If the cyclic plastic deformation is dependent on frequency and temperature, $\mathrm{da} / \mathrm{dN}$ will be weakly dependent on frequency and temperature.

In Figure 5, between the low-frequency faster intergranular fatigue crack growth caused by the intermittent micro-ruptures, and the high-frequency slower transgranular intrinsic fatigue crack growth due to cyclic plastic deformation, there exists a region of mixed mode of both intergranular and transgranular crack growth, as observed by Pelloux and Huang [46]. 


\section{DISCUSSIONS}

The accelerated fatigue crack growth at elevated temperatures has been attributed to either oxidation or creep damage. Both oxidation and creep have been shown as possible mechanisms for the high temperature fatigue damage. Grain boundary void formation and cavitation are the result of surface diffusion and/or grain boundary vacancy diffusion, while grain boundary oxidation is primarily caused by the diffusion of oxygen. The kinetics of the diffusions of vacancies and oxygen atoms is shown schematically in Figure (7). The figure indicates that one mechanism dominates in the high temperature region and the other dominates in the low temperature region. Therefore, the question is not which one of these two mechanisms causes high temperature fatigue damage. The problem is to define the different regions dominated by these two different mechanisms.

The quantitative relations between the diffusion rates and the rate of oxide rupture and the rate of nucleation and growth of voids and cavities, and their relations with fatigue crack growth have not yet been established. It is obvious that fatigue crack growth rate is not necessarily linearly proportional to the diffusion rates, therefore, the activation energy for diffusion may not be equal to the "activation energy" for fatigue crack growth. The functional relationships between $\mathrm{da} / \mathrm{dN}$ and the diffusion rates of vacancies and oxygen atoms depend on the detailed physical processes of fatigue crack growth. If a simple power relationship exists between $\mathrm{da} / \mathrm{dN}$ and diffusion rate, then the rate, $\mathrm{R}$ (in Figure 7 ) can also be interpreted as the crack growth rate caused by the diffusion process. 
Without a clear understanding of the underlying reasons for the observed fatigue crack growth behaviors, it is difficult and unsafe to extrapolate a limited amount of experimental data to make fatigue life predictions. For example, to extrapolate the crack growth data in Figure 5, from the low frequency region into the high frequency region or vise versa will underestimate the crack growth rate. Therefore 1 t is unsafe.

If creep is the damage mechanisms for high temperature fatigue, and if grain boundary creep cavitation is induced by a tensile stress together with vacancy diffusion, the tensile stress in a redundant structure will decrease by creep stress relaxation, and the decreased tensile stress will reduce the rate of cavitation. Thermal stress is a transient stress. Thermal stress will be relaxed as creep deformation takes place. In a sense, it is "redundant". Therefore, creep damage may not be as important in thermal fatigue or thermalmechanical fatigue in structural components, where creep relaxation takes place.

Multidisciplinary studies based on empirically observed physical processes are needed to develop mechanistic and quantitative models for oxidation damage and creep damage in high temperature fatigue. The first step in the development of such models for oxidation damage is a quantitative analysis of grain boundary oxidation.

The high temperature fatigue crack growth model of intermittent micro-ruptures of grain boundary oxides gives an inverse relationship between fatigue crack growth rate, da/dN and the cyclic frequency, $v$. This inverse relation is observed for a number of high temperature alloys 
in the low frequency region. Grain boundary oxidation is certainly a possible mechanism for the accelerated fatigue crack growth at elevated temperatures.

Grain boundary oxidation was studied for samples free of stress. The effects of an applied stress and an imposed cyclic strain on the diffusion of oxygen and oxidation still need to be addressed.

Equation (1) is for grain boundary bulk oxide penetration. It is conceivable that even a monolayer of oxide will reduce the grain boundary cohesive strength and will accelerate fatigue crack growth. As indicated by the above discussion on the needs for additional knowledge, the work on the effects of oxidation on high temperature fatigue life is far from completed. This study is only one of the initial steps to construct a mechanistic and quantitative model based on the empirical data of grain boundary oxide penetration. 
V. SUMMARY AND CONCLUSIONS

Grain boundary oxidation may accelerate fatigue crack growth at elevated temperatures. The grain boundary oxidation kinetics was studied. Grain boundary oxide penetration depth varies widely from one grain boundary to another. The measured grain boundary oxide penetration data agree well with the Welbull distribution. A model of intermittent micro-ruptures of the grain boundary oxide is constructed for the accelerated fatigue crack growth at elevated temperatures. The derived fatglue crack growth rate based on the model agrees well with the observed inverse relation between $\mathrm{da} / \mathrm{dN}$ for a number of high temperature alloys. 


\section{References}

[1] L.F. Coffin, Jr., "Fatigue at High Temperature - Prediction and Interpretation," Proc. Instm. Mech. Engrs. 188, 109 (1974).

[2] S.S. Manson, G.R. Halford, and M.H. H1rschberg, "Creep-Fatigue Analysis by Strainrange Partitioning", NASA TM X-67838 (1971).

[3] S.S. Manson, G.R. Halford, and M.H. Hirschberg, "Strainrange Partitioning - A Tool for Characterizing High Temperature, Low Cycle Fatigue", NASA TM X-7169.1. (1975).

[4] D. Hull and D.E. Rimmer, "The Growth of Grain-Boundary Voids under Stress", Phil. Mag. 4, 673 (1959).

[5] R.G. Fleck, D.M.R. Taplin, and C.J. Beevers,

"An Investigation of the Nucleation of Creep Cavities by IMV Electron Microscopy", Acta Met. 23, 415 (1975).

[6] B.J. Cane and G.W. Greenwood, "The Nucleation and Growth of Cavities in Iron during Deformation at Elevated Temperatures", Metal Sci. 9, 55 (1975).

[7] T.-J. Chuang, and.J.R. Rice, "The Shape of Intergranular Cracks Growing by Surface Diffusion", Acta Met. 21, 1625. (1973).

[8] R. Raj and M.F. Ashby, "Intergranular Fracture at Elevated Temperature", Acta Met. 23, 653 (1975).

[9] M.V. Speight and W. Beere, "Vacancy Potential and Voids Growth on Grain Boundaries", Metal Sci. 9, 190 (1975).

[10] W. Beere and M.V. Speight, : "Creep Cavitation by Vacancy Diffusion in Plastically Deforming Solid", Metal Sci. 12, 172 (1978).

[11] T.-J. Chuang, K.I. Kagawa, J.R. Rice, and L.B. Sil1s, "NonEquilibrium Models for Diffusive Cavitation of Grain Interfaces", Acta Met. 27, 265 (1979).

[12] R. Raj, "Nucleation of Cavities at Second Phase Particles in Grain-Boundaries", Acta Met., 26, 995 (1978).

[13] G.H. Edward and M.F. Ashby, "Intergranular Fracture During Power-Law Creep", Acta Met., 27, 1505 (1979).

[14] A. Needleman, and J.R. Rice, "Plastic Creep Flow Effects in Diffusive Cavitation of Grain-Boundaries", Division of Engr. Report, Brown University. (1980).

[15] A.S. Argon, I.W. Chen, and C.W. Lau, "Intergranular Cavitation in Creep: Theory and Experiments", "Creep-Fatigue-Environment Interaction" ed. by Pelloux, R.M. and Stolo66, N.S., AIME, 46 (1980).

[16] J.L. Bassani, and A. Saxena, "Time-Dependent Fatigue Crack Growth Behavior at Elevated Temperature", Minnowbrook Conference on "Life Prediction for High Temperature Gas Turbine Materials", EPRI, (1980). 
[17] Y. Oshida and H.W. Liu, "Oxidation and Low Cycle Fatigue Life Prediction", Proc. of the Third Annual Workshop on Turbine Hot Section Technology (HOST) Project, 321 (1984).

[18] L.F. Coffin, Jr., "The Effect of High Vacuum on the Low Cycle Fatigue Law", Met. Trans. 7, 1777.(1972).

[19] H.D. Solomon, "Low Cycle Fatigue Crack Propagation in 1018 Stee1", Jour. of Mats. 7, 299 (1972).

[20] H.D. Solomon, "Frequency. Dependent Low Cycle Fatigue Crack Propagation", Met. Trans. 4, 341 (1973).

[21] H.D. Solomon, and L.F. Coffin, Jr., "Effects of Frequency and Envi ronment on Fatigue Crack Growth in A286 at $1100^{\circ} \mathrm{F}^{\prime \prime}$, ASTM STP 520 on "Fatigue at Elevated Temperature" (1973).

[22] L.A. James, and R.L. Knecht, "Fatigue-Crack Propagation Behavior of Type 304 Stainless Steel in a Liquid Sodium Environment", Metal Trans. 6, 109 (1975).

[23] L.A. James, "Some Questions Regarding the Interaction of Creep and Fatigue", Jour. of Eng. Materials and Technology, ASME, $98,235(1976)$.

[24] M.W. Mahoney and N.E. Paton, "The Influence of Gas Environments on Fatigue Crack Growth Rates in Types 316 and 321 Stainless Stee1s", Nuclear Tech., 23, 290 (1974).

[25] G.J. Hill," "The Failure of Wrought $1 \% \mathrm{Cr}-\mathrm{M}-\mathrm{V}$ Steel in ReverseBending High Strain Fatigue at $530^{\circ} \mathrm{C} "$. Thermal and High-Strain Fatigue, The Metals and Metallurgy Trust, 312 (1967).

[26] D.J. White, "Effect of Environment and Hold Time on the High Strain Fatigue Endurance of $1 / 2$ percent Molybdenum Steel", Porc.

Inst. of Mech. Engineers, Part 1, 184, 223 (1969).

[27] A.J. Nachtigal, S.J. Klima, J.C. Freche and C.A. Hoffman,. "The Effect of Vacuum on the Fatigue and Stress-Rupture Properties of S-186 and Inconel 550 at $1500^{\circ} \mathrm{F}^{\prime \prime}$, NASA Tech. Note D-2898 (1965).

[28] H.W. Liu and J.J. McGowan,. "A Kinetic Analysis of High Temperature Fatigue Crack Growth", Scripla Met. 15, 507 (1981).

[29] J.J. McGowan and H.W. Liu, "A Design Approach for Correlating High Temperature Fatigue Crack Growth Over a Wide Range of Papameters", Jour. of Eng. Mats. and Tech. Trans. ASME, 103, 246. (1981).

[30] S.D. Antolovich, S. Liu and R. Baur, "Low Cycle Fatigue Behavior of Rene 80 at Elevated Temperature", Met, Irans. 12A, 473 (1981).

[31] Y. Oshida and H.W. Liu, "Grain Boundary Oxidation and an Analysis of the Effects of Pre-Oxidation on Subsequent Fatigue Life", ASTM Symposium on "Low Cycle Fatigue - Direction for the Future" (1985). 
[32] J. Reuchet and L. Remy, "High Temperature Fatigue Behavior of a Cast Cobalt-Base Superalloy", Fatigue of Engr. Materials and Structures, 2, p. 51 (1979).

[33] J. Reuchet and L. : Remy, "Fatigue Oxidation Interaction in a SuperalloyApproach of Life Prediction in High Temperature Low Cycle Fatigue", Met. Trans., 14A, p. 141. (1983).

[34] F.H. Stott, G.C. Wood, Y. Shida, D.P. Whittle, and B.D. Bastow, "The Development of Internal and Intergranular Oxides in NickelChromium-Aluminum Alloys at High Temperature", Conr. Sci., 21, p. 599 (1981).

[35] Y. Shida, G.C. Wood, F.H. Stott, D.P. Whittle and B.D. Bastow "Intergranular Oxidation and Interal Void Formation in Ni-40\% Cr Alloys", Corr. Sci., 21, p.581, (1981).

[36] L. Couling and R. Smoluchowshi, "Anisotropy of Diffusion in Grain Boundaries", J. Appl. Phys. 25, 1538. (1954).

[37] W.R. Upthegrove and N.J. Sinnot, "Grain Boundary Se1fDiffusion of Nickel", Trans. ASM, 50, (1958).

[38] D. Turnbull and R. Hoffman, "The Effect of Relative Crystal and Boundary Orientations of Grain Boundary Diffusion Rates", Acta Met. 2, 419. (1954).

[39] R.T.P. Whipple, "Concentration Contours in Grain Boundary Diffusion", Phil. Mag. 45, 1225. (1954).

[40] R.M. Wallace, C.G. Annis, Jr., and D.L. Sims, "Application of Fracture Mechanics at Elevated Temperatures". AFML-TR-76-176 (1976).

[41] J.M. Larsen, B.J. Schwartz and C.G. Annis, Jr., "Cumulative Damage Fracture Mechanics Under Engine Spectra", AFML-TR-79-4159 (1980).

[42] D.E. Macha, "Fatigue Crack Growth Retardation Behavior of IN-100 at Elevated Temperature", Eng. Fracture Mechanics, 12, 1 (1979).

[43] T. Weerasooriya and T. Nicholas, "Hold-Time Effects in Elevated Temperature Fatigue Crack Propagation", AFWAL-TR-84-4184, (1985).

[44] F. Garrielli and R.M. Pelloux, "Effect of Environment on Fatigue and Creep Crack Growth in Inconnel X-750 at Elevated Temperature", Met. Trans. 13A, 10.83 (1982).

[45] M. Zhou and F. Gabrielli, "Some Aspects of Frequency on High Temperature Fatigue in Inconnel X-750", Z. Metallkde, 74, 639 (1983).

[46] R.M. Pelloux and J.S. Huang, "Creep-Fatigue-Environment Interactions in Astroloy", "Creep-Fatigue-Environment Interaction" ed. by R.M. Pelloux and N.S. Stolo6́6. AIME, 151 (1980). 
[47] K.M. Nikbin and G.A. Webster, "Prediction of Crack Growth Under Creep-Fatigue Loading Conditions", ASTM Symposium on "Low Cycle Fatigue - Direction for the Future" (1985).

[48] L.A. James, "The Effect of Frequency upon the Fatigue-Crack Growth of Types 304 Stainless Steel at $1000^{\circ} \mathrm{F}^{\prime \prime}$ ASTM STP 513 on "Stress Analysis and Growth of Cracks", 218. (1972).

[49] S.D. Antolovich, E. Rosa, and A. Pineau, "Low Cycle Fatigue of Rene 77 at Elevated Temperatures", Mat. Sci. and Engr., 47, 47 (1981). 
ORIGINAL PAG

OF POOR QUALTY

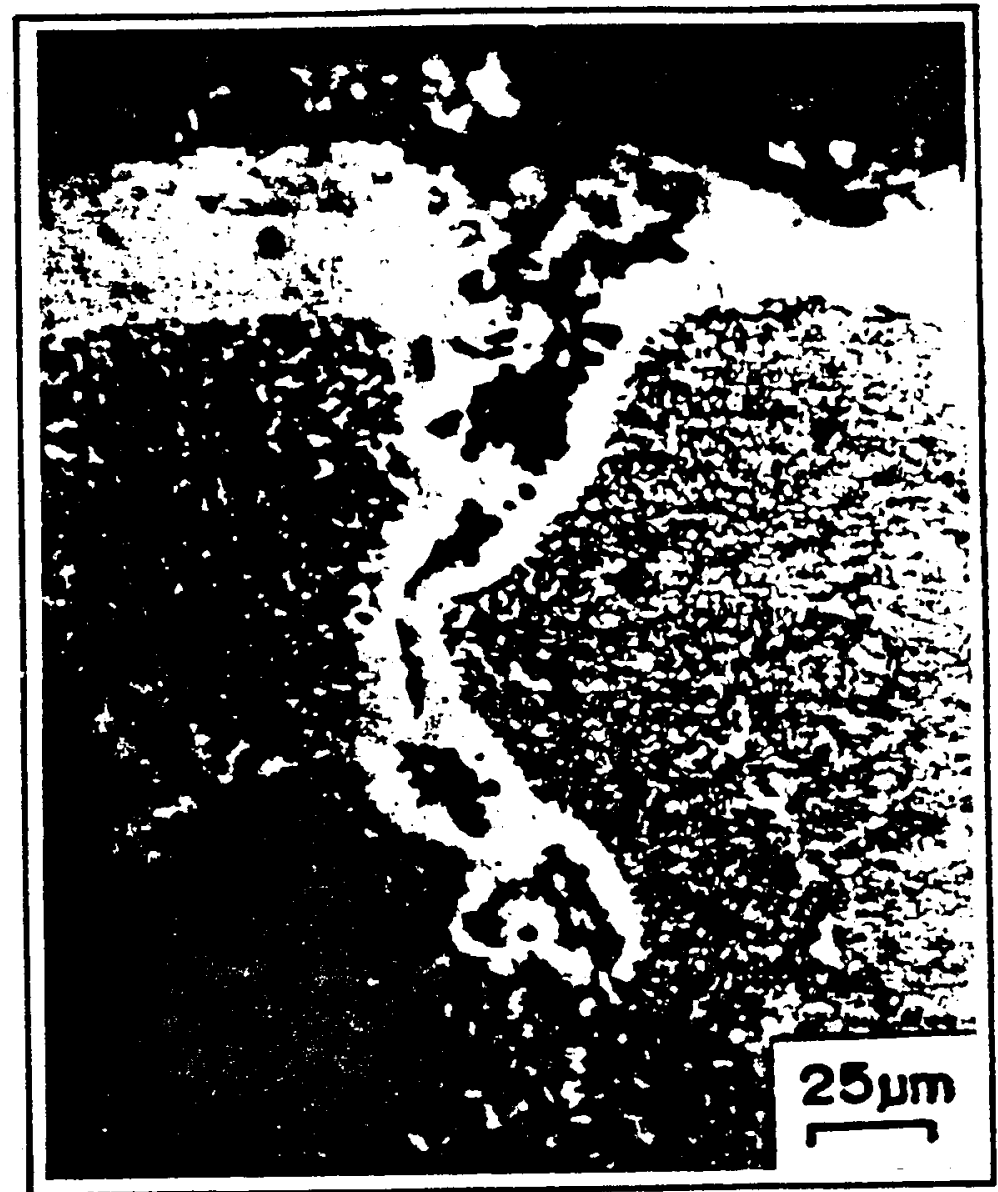
Figure 1 Cross-section of oxidized coupon of TAX-8A at
$1000^{\circ} \mathrm{C}$ for 500 hours 


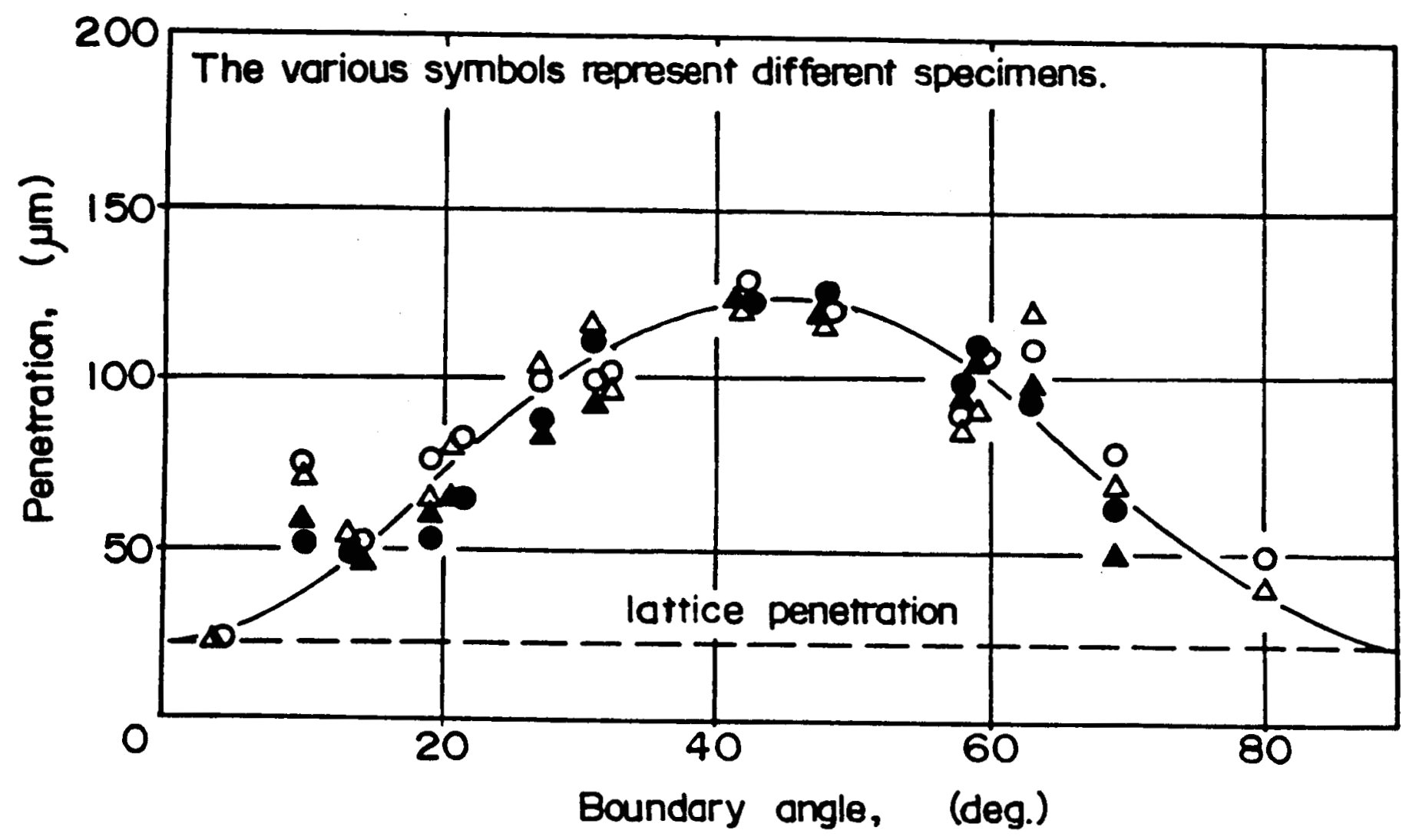

Figure 2 Grain boundary angle effect on the penetration of radioactive nickel along nickel bicrystals grain boundaries at $1050^{\circ} \mathrm{C}(37)$ 


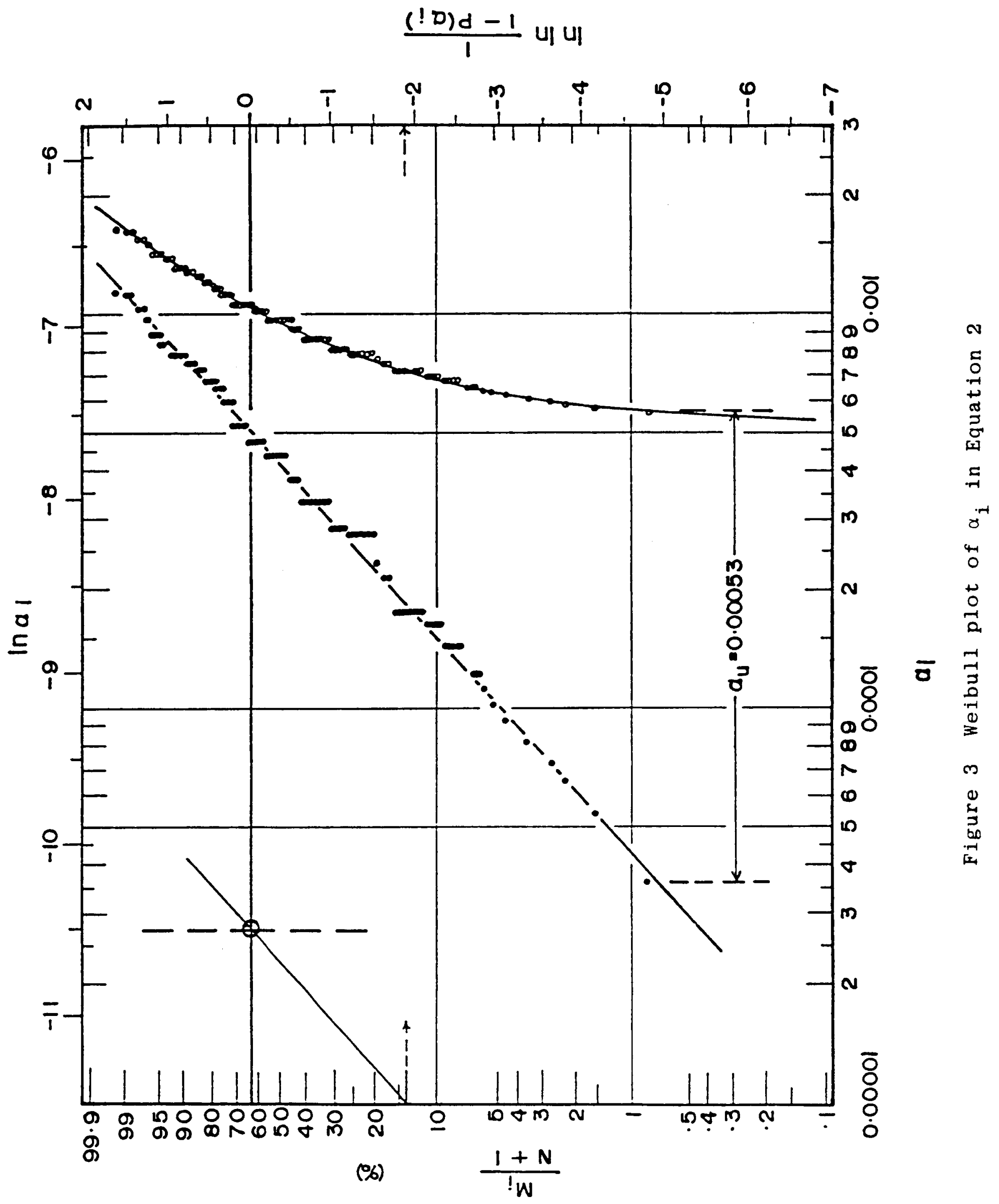



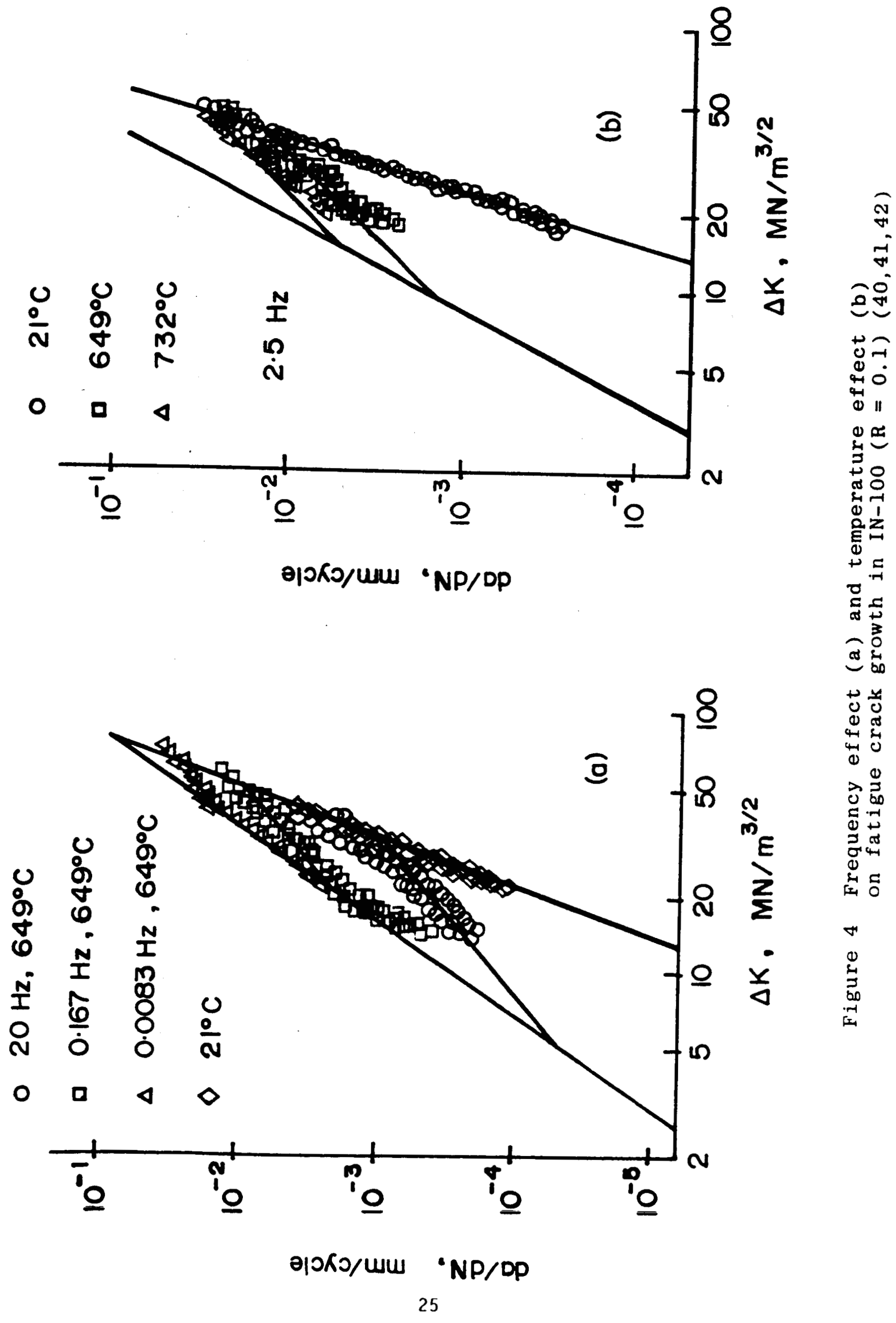


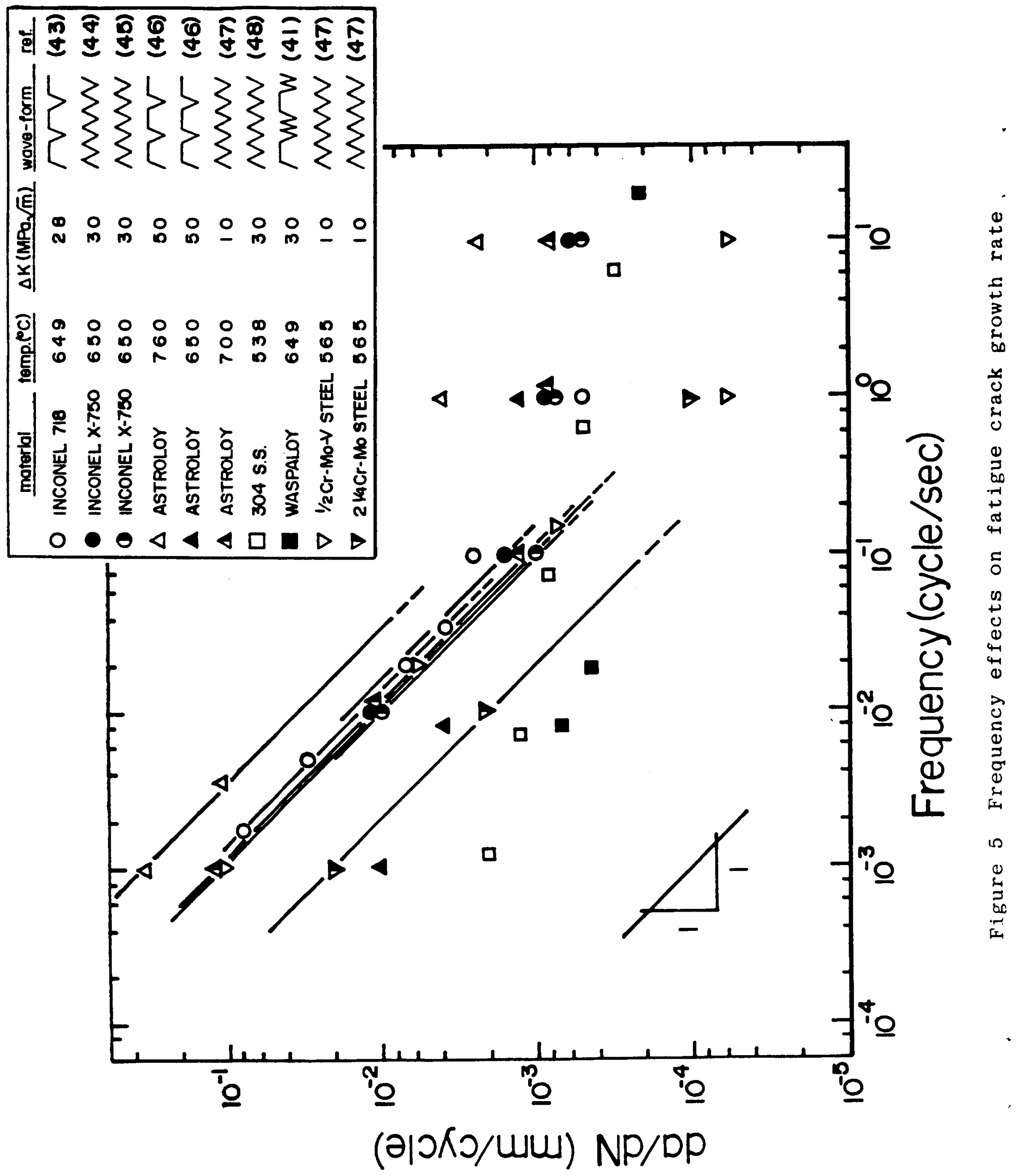




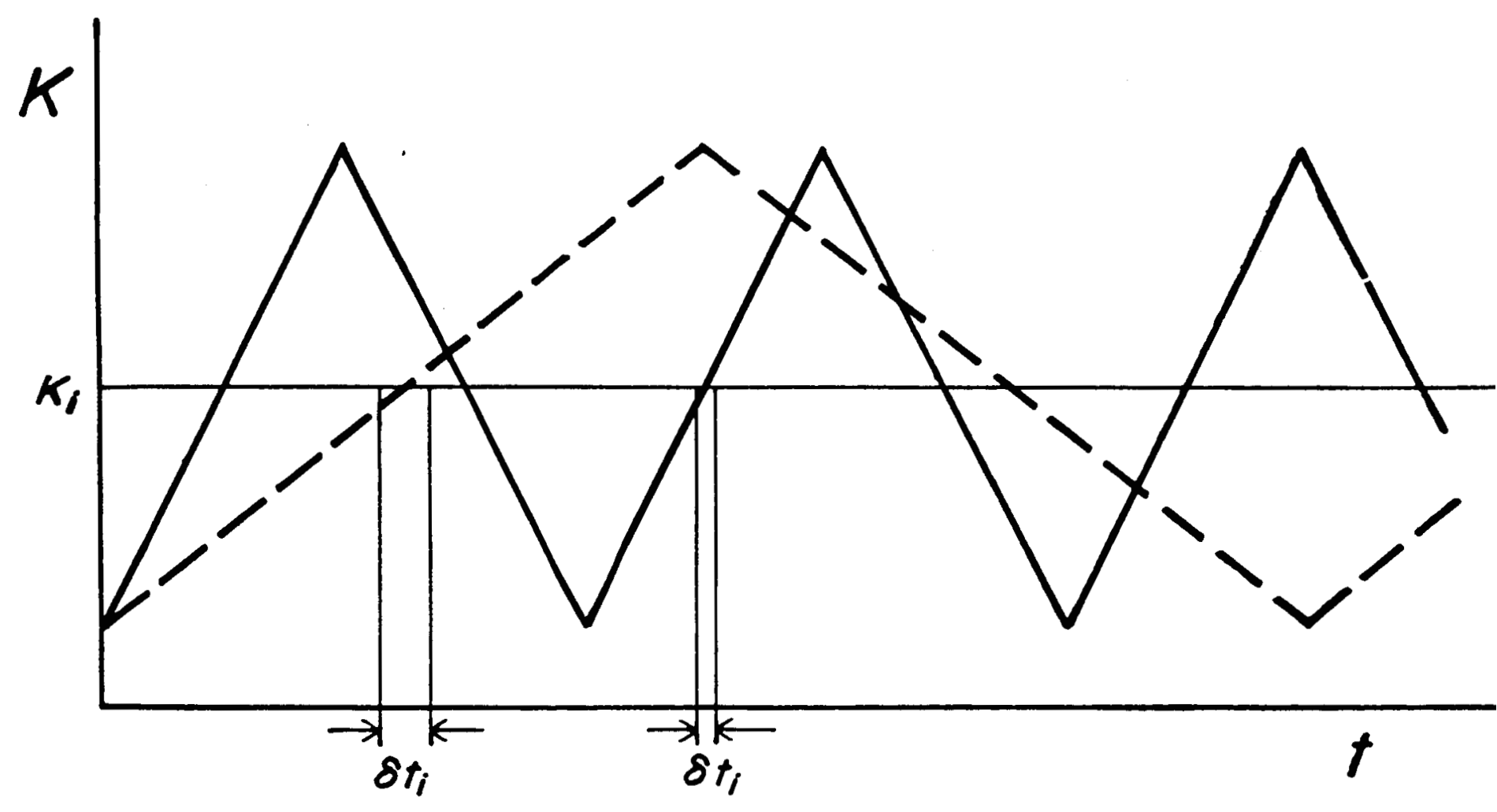

Figure 6 Cyclic loading at two different frequencies 


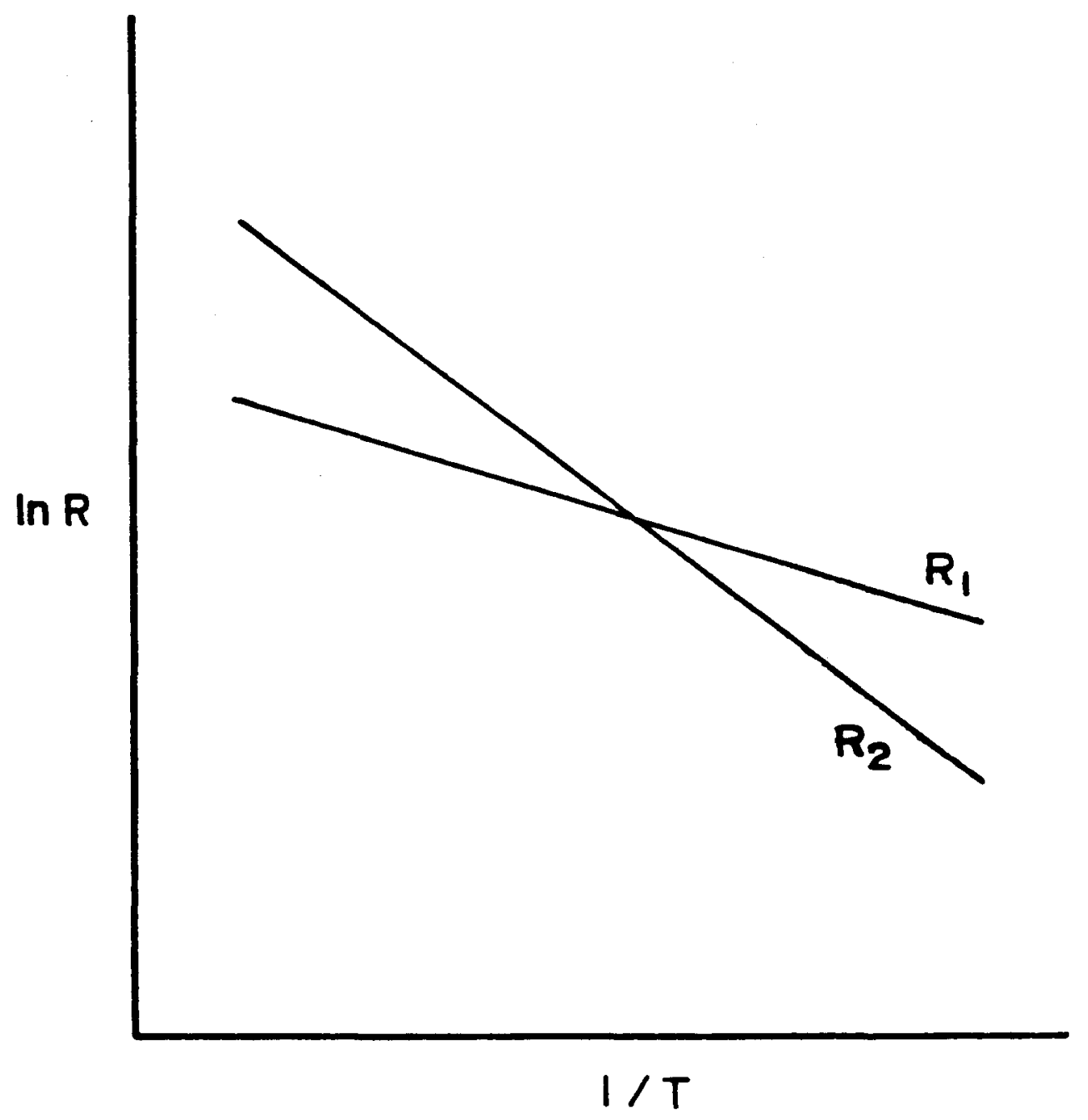

Figure 7 The schematic plot of two rate processes 


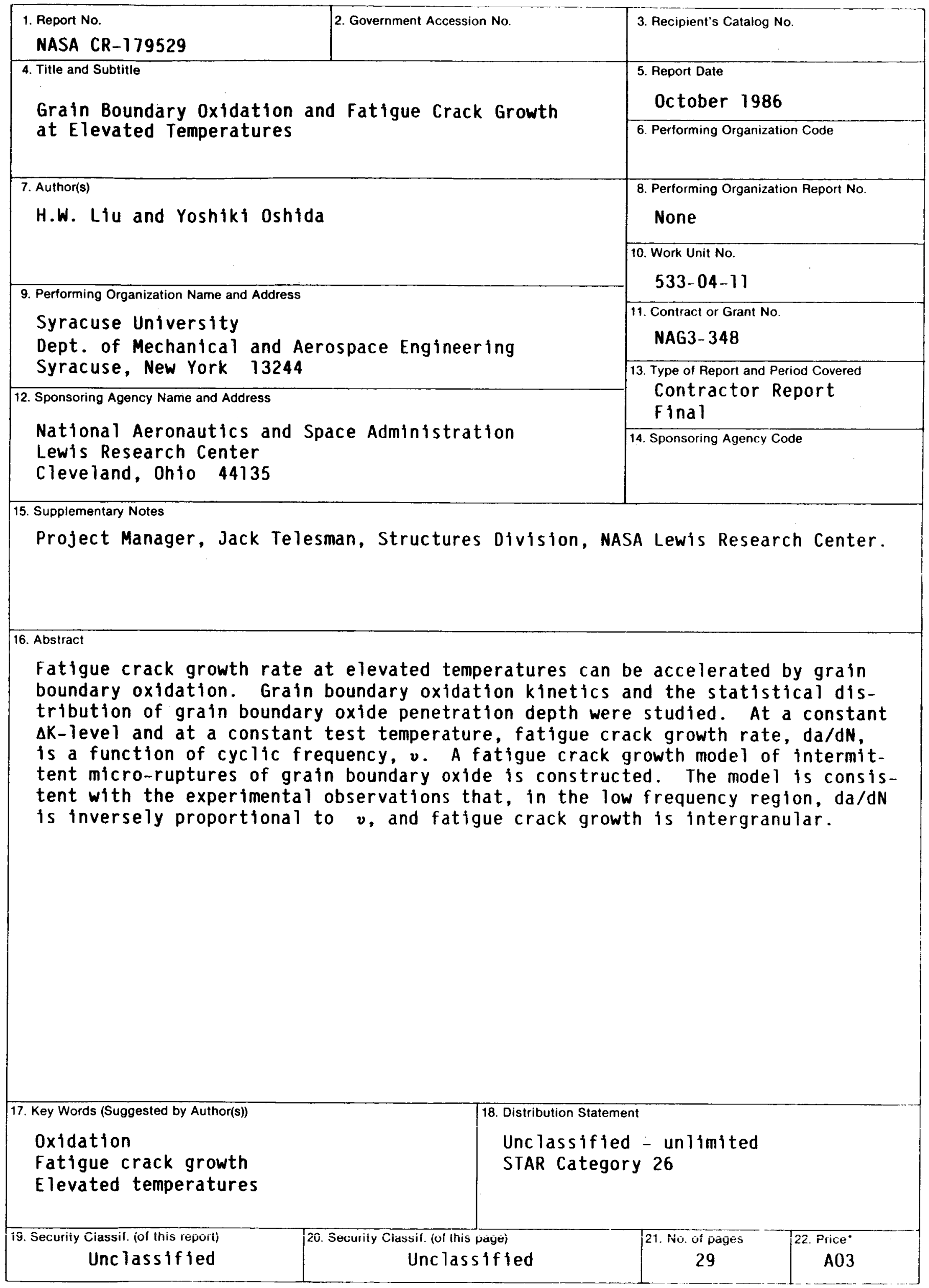

*For sale by the National Technical Information Service, Springfield, Virginia 22161 